\title{
News from the Underground
}

\section{Juniors' education and ongoing training as additional research pillars of respiratory medicine}

Spring and summer are usually considered times for relaxation and leisure; however, this is not the case for the European Respiratory Society (ERS) Junior Members Committee (JMC). There was not much time to pack after 12th ERS Lung Science Conference before we met again in Berlin, Germany at the ERS Educational Research Seminar in May. The ERS Educational Research Seminar, organised by Anita Simonds (ERS Education Council chair), aimed to keep ERS at the cutting edge of medical education. The burning problems, key issues and future developments in medical education for respiratory specialists and trainees in Europe were discussed. The JMC was represented by: Indre Butiene, our chair and the only junior member in the Faculty; Anders Bjerg, Georgia Hardavella, Tiago Jacinto and Szymon Skoczynski, who were invited as participants; and Alexander Mathioutakis and Rica Zinsky, who were both active in the formation of the JMC.

All junior members are grateful to the organisers for the opportunity to participate in this outstanding, dynamic and instructive 2-day seminar that covered all areas of respiratory education including medical trainees, specialists, allied healthcare professionals and patients.

Great emphasis was given to competencybased training in Europe and its diversity throughout European countries, as well as ways to overcome implementation barriers. Lessons learnt from the HERMES (Harmonised Education in Respiratory
Medicine for European Specialists) experience have generated ideas to overcome difficulties in future implementation.

The first day of the debate was dedicated to analysis of the current achievements of HERMES and tasks for the future. The novel application of simulators in medical training has emerged as a "hot topic"; however, from a European perspective, further facilitation is needed as this modality is currently only available in a few European centres.

We need to underline that education and quality assessment should be considered ongoing processes. The fourth phase of the HERMES programme in adult respiratory medicine extended beyond individual skills: the need for professional training led to creation of a set of minimal criteria required for a centre to be granted a certificate of excellence for education in respiratory medicine training. We are pleased to report that there is now a JMC representative on the committee for the Accreditation of Training Centres in Adult Respiratory Medicine.

Huge emphasis was given to training of scientists and allied healthcare professionals in respiratory medicine, which was discussed on the basis of experience achieved during the ongoing and successful ERS Spirometry Driving Licence initiative. Another important topic addressed was the future place of "traditional paper journals" in medical science. According to presented data, this form of medical publishing in unlikely to be maintained in its present form in the coming 
years. The time from submission to publication and, more importantly, wide accessibility seem to play a major role in this process. Exciting examples of this process will include new online educational tools in respiratory medicine from ERS.

During the first day, emphasis was given to physician performance and assessment. In one of the sessions, Jason Frank (Office of Specialty Education, Royal College of Physicians and Surgeons of Canada) made a convincing case that the quality of physician performance is more related to the supervisor than to the trainee doctor's personal skills. This point raised a "hot question" for juniors: how to assess and train the trainer?

At the end of the first day, the keynote presentation "Magic, Medicine and Medical Ethics" by Daniel K. Sokol (London, UK) triggered further thoughts on the place of evidence-based medicine from the perspective of historical data. One could say that the current search for medical evidence cannot be further improved. However, we have to remember that most of the current medical evidence with strong impact is industry-based evidence, which raises concerns over bias. One obvious solution is broader, mandatory and unbiased training in statistics and evidencebased medicine for medical professionals.

The second day of the meeting focused on accreditation, continuing medical education (CME) and involvement of patients in the training of respiratory teams. Three presentations highlighted the current and future activities of the European Lung Foundation, which are of crucial importance for the connection of patients with health professionals. The discussion of CME focused on an European approach for CME needs assessment, and the way forward, in particular with the Journal of European CME. The second half of the morning involved group discussions on the following topics: 1) measuring outcomes of competency-based education; 2) blue-sky approaches to education; and 3) the future role of medical societies in medical education. The discussions were very productive and open-minded, and it was a joyful brainstorming activity.
Junior delegates were involved in all sessions, and provided several suggestions that could help and improve the activities reflected in the main topics. The meeting ended with a general meeting, in which all groups provided feedback from their discussions, and the key messages were summarised, presented and fine-tuned. Finally, Anita Simonds and Jaimu Busari (Maastricht, the Netherlands) wrapped up with a discussion of the working document that will contain the final messages of this very interesting meeting.

Indre Butiene attended the ERS Presidential Summit "Breaking down barriers to lung health: a better environment for better medicines" on July 2-3, 2014, in Rome, Italy. Medical professionals, patients, the pharmaceutical industry, funders and policymakers examined various barriers to new medical products, from research to regulatory issues, and explored new ways to create a better environment for medicine development. Training of young specialists in performing clinical trials, possibilities for broader involvement in translational research and the types of fellowships provided by ERS were discussed during the meeting.

Please remember that the ERS International Congress is just around the corner and ready to have a positive impact on your career. We do hope that your scientific efforts will be rewarded in Munich, Germany. Congratulations to all junior members with accepted abstracts! Please remember that useful advice for poster and/or oral presentations may be found in previous issues of Breathe $[1,2]$. We would like to congratulate those junior members who have been invited to chair sessions. We hope that you will enjoy the task and that your Munich performance will open more chairing possibilities for juniors at future ERS International Congresses. We have prepared some tips to help you; please read the article in the June issue of Breathe [3].

We are looking forward to see you at the ERS International Congress in Munich. Please come and visit us at the ERS stand and at other events with JMC participation organised by ERS.
Underground is written by

representatives of the ERS Junior Members Committee: Tiago Jacinto, Indre Butiene, Georgia Hardavella, Szymon Skoczynski

\section{References}

1. Jacinto T, Hardavella G, Saad N, et al. Doing Science: Oral presentations. Breathe 2014; 10: 79-81.

2. Jacinto T, Hardavella G, Saad N, et al. Doing Science: Preparing a poster. Breathe 2013; 9: 505-507.
3. Hardavella G, Saad NJ, Caudri D, et al. Doing Science: Chairing sessions. Breathe 2014; 10: 165-168. 